\title{
Evaluation of laser iridectomy in angle-closure glaucoma: provocative tests
}

\author{
G. KARMON, T. VENDER, AND H. SAVIR \\ From the Department of Ophthalmology, Hasharon Hospital, Petah-Tiqva, \\ and Tel Aviv University Medical School, Israel
}

SUMMARY An argon laser iridectomy was performed on 18 eyes of 14 patients with closed-angle glaucoma. The intraocular pressure (IOP) was controlled in all but one eye within normal limits. Variable amounts of pigment were found on gonioscopy in all cases. The mydriasis test was positive in one eye $(5.5 \%)$ after homatropine and in 5 eyes $(28 \%)$ after tropicamide drops. $80 \%$ of the positive results occurred in lightly pigmented irides. The dark-prone position test was positive in 7 eyes $(38 \%), 71 \%$ of the positive results occurring in heavily pigmented irides. Tonography was also performed; the possibility of trabecular damage is discussed.

Since Meyer-Schwickerath's ${ }^{1}$ first iridectomy with the use of a xenon arc photocoagulator other sources of radiant energy have been used, first the ruby laser operating at a wavelength of $694 \mathrm{~nm},,^{23}$ and later on the continuous-wave argon laser operating at 488 and $515 \mathrm{~nm}$, thus permitting the absorption of excessive heat by the circulating red blood cells. Khuri ${ }^{4}$ working with rabbits and other workers ${ }^{5-10}$ treating patients reported their experience in producing successful iridectomies.

Laser iridectomy is becoming increasingly popular as an alternative to surgical iridectomy. Various authors stress different aspects of the technique they used-for example, the amount of energy, the differences between the colour of the treated irides, etc. We report in this study the results of postoperative provocative tests in 18 eyes with successfully produced laser iridectomies.

\section{Materials and methods}

Eighteen eyes of 14 patients were examined (Table 1). These were consecutive cases of laser iridectomy treated by a continuous-wave coherent 900 argon laser adapted to a Zeiss slit-lamp biomicroscope.

The iridectomy was performed through a clear cornea without the use of a contact lens in a singlephase multiburn technique. The beam was aimed at

Correspondence to Dr G. Karmon, Department of Ophthalmology, Hasharon Hospital, Petah-Tiqva, Israel. the upper temporal or nasal quadrant 1 to $2 \mathrm{~mm}$ from the limbus. The coherent 900 continuous-wave argon laser settings used were $50 \mu \mathrm{m}$ spot size, $0 \cdot 1$ second duration, and peak energies of 1500 to $2000 \mathrm{~mW}$. .

\begin{tabular}{lc} 
Table $1 \quad$ Details of patients in the study \\
\hline $\begin{array}{l}\text { Number of patients } \\
\text { Number of eyes }\end{array}$ & 14 \\
Age range (mean $65 \cdot 3$ years) & 18 \\
$\begin{array}{l}\text { Sex: } \\
\quad \text { male }\end{array}$ & $41-78$ \\
$\quad$ female & 5 \\
$\quad \begin{array}{l}\text { Iris colour (eyes): } \\
\quad \text { light pigment (blue and hazel) }\end{array}$ & 9 \\
$\quad$ heavy pigment (brown) & 10 \\
$\begin{array}{l}\text { Diagnosis (eyes): } \\
\quad \text { acute angle closure } \\
\text { chronic angle closure }\end{array}$ & 8 \\
\hline
\end{tabular}

Prior to the treatment miosis was achieved by instilling a few drops of $2 \%$ pilocarpine hydrochloride. At the end of the procedure dexamethasone-neomycin drops were instilled 6 times daily for 24 hours.

During the treatment a cloud of dispersed pigment and an air bubble originating from the posterior chamber were often observed. The procedure was considered successful when the anterior capsule of the lens was visualised through the iridectomy and positive transillumination was obtained.

One to 3 sessions were needed to obtain a patent 
coloboma. In brown eyes a me; of 2.5 sessions was needed compared with 1.75 sess $n s$ in blue and hazel eyes. The number of burns need $\mathrm{d}$ to achieve the goal varied from patient to patient. It ranged from 54 to 280 , but as a rule more burns $w$ re needed in heavily pigmented (mean $171 \cdot 4)$ than $n$ lightly pigmented irides (mean 128.0).

The patients were followed up monthly for 3 to 15 months, mean of 8.4 mon' 's. Gonioscopy was performed before and after the iridectomies. Kinetic perimetry (with a Haag-Streit Goldmann perimeter), cup-disc ratio determination, and tonography were done in all cases by the same person. In one patient (no. 10) tonography was performed before and after the procedure and the results were compared.

The mydriasis test was done several months after iridectomy, the intraocular pressure (IOP) being measured up to one hour after instillation of 2 drops of tropicamide $1 \%$, and 1 week later when the test was repeated with homatropine $1 \%$.

The dark-prone position test was performed as follows: the IOP was measured with a Goldmann applanation tonometer. The patient then lay face down on a nearby couch with his forehead resting on a pillow in a dark room. He was instructed to keep his eyes open and was observed from time to time to ascertain that he was alert and not asleep. After one hour the IOP was measured, the only source of light being the blue light of the Goldmann applanation tonometer. The measurements were repeated until the IOP returned to its original level.

\section{Results}

The argon laser produced a patent coloboma in all the eyes. Blue eyes were slightly more difficult to penetrate, and 3 blue eyes showed an incompletely penetrated anterior iris but a wide hole in the posterior iris with a clear retroillumination on biomicroscopy.

The IOP ranged from 11 to $20 \mathrm{mmHg}$ in 17 eyes and $26 \mathrm{mmHg}$ in one eye (patient no. 4) without medication.

Corneal opacities (epithelial and/or endothelial), when present immediately after treatment, disappeared within a few days. Small anterior focal lenticular opacities near the coloboma developed in 3 eyes, but they did not progress during the follow-up period.

On the day of treatment a low-grade iritis developed in all cases, but it subsided within 24 hours on a regimen of topical steroid drops 6 times daily. A slightly dragged pupil was observed in 5 eyes. Slight posterior synechiae were found in 5 eyes, but only in one eye (patient no. 1) with a blue iris were they extensive.
On gonioscopy pigment was found in all cases. extending from 4 to 7 o'clock in variable amounts. In 3 eyes a wide bridge of pigment spanning the angle was present. No pigment was found before the laser treatment in any of the eyes. An attempt to grade the amount of pigment in order to evaluate a possible difference between lightly and heavily pigmented irides showed no significant difference.

The results of the provocative tests are listed in Table 2. The dark-prone position test was positive (an IOP increase of $8 \mathrm{mmHg}$ or more) in 7 eyes $(38 \%)$; the mydriasis test was positive (an IOP increase of 8 $\mathrm{mmHg}$ or more) in one eye (5.5\%) after homatropine drops and in 5 eyes (28\%) after tropicamide drops.

Table 2 Results of provocative tests

\begin{tabular}{|c|c|c|c|c|c|}
\hline \multirow{3}{*}{$\begin{array}{l}\text { Patient } \\
\text { no. }\end{array}$} & \multirow[t]{3}{*}{ Eye } & \multirow{3}{*}{$\begin{array}{l}\text { Iris } \\
\text { colour* }\end{array}$} & \multicolumn{3}{|c|}{$I O P$ increase in $\mathrm{mm} H g$} \\
\hline & & & \multicolumn{2}{|l|}{ Mydriasis } & \multirow{2}{*}{$\begin{array}{l}\text { Dark-prone } \\
\text { test }\end{array}$} \\
\hline & & & Tropicamide & Homatropine & \\
\hline 1 & OD & L & 2 & 0 & 0 \\
\hline 2 & OD & $\mathrm{L}$ & 0 & 0 & 5 \\
\hline 3 & OS & B & 8 & 3 & 3 \\
\hline 4 & $\cdot \mathrm{OD}$ & B & 3 & 2 & 3 \\
\hline 5 & OD & B & 3 & 2 & 8 \\
\hline 6 & OD & B & 0 & 2 & 8 \\
\hline 6 & OS & B & 0 & 2 & 10 \\
\hline 7 & OD & $\mathbf{L}$ & 8 & 5 & 5 \\
\hline 7 & OS & $\mathbf{L}$ & 9 & 6 & 5 \\
\hline 8 & OD & $\mathbf{L}$ & 3 & 2 & 14 \\
\hline 9 & OS & B & 6 & 0 & 14 \\
\hline 10 & OS & $\mathbf{L}$ & 8 & 1 & 6 \\
\hline 11 & OD & $\mathbf{L}$ & 4 & 2 & 3 \\
\hline 11 & OS & $\mathbf{L}$ & 4 & 2 & 4 \\
\hline 12 & OD & B & 2 & 9 & 13 \\
\hline 13 & OS & B & 5 & 1 & 0 \\
\hline 14 & OD & $\mathbf{L}$ & 4 & 0 & 8 \\
\hline 14 & OS & $\mathbf{L}$ & 8 & 1 & 1 \\
\hline
\end{tabular}

${ }^{*} \mathrm{~L}=$ lightly pigmented iris. $\mathrm{B}=$ brown iris.

The positive results of the provocative tests in the lightly and heavily pigmented irides (Table 3 ) showed that a positive result after tropicamide occurred in 4 lightly pigmented irides, whereas the dark-prone position test was positive in 5 heavily pigmented irides.

Tonography revealed that in 16 of 18 eyes there was evidence of a decreased trabecular outflow after laser iridectomy. Pretreatment data were available in only one eye (patient no. 10), the patient being on a regimen of pilocarpine $2 \% 3$ times daily (Table 4). The tonography was repeated in the untreated eye as well, the results being similar to those obtained earlier $(C=0 \cdot 24$; Becker index $=100)$.

Fundus examination was performed and showed no retinal damage in any case. Fluorescein angiographic and static perimetry studies were also done. and the results will be published later. 
Table 3 Positive provocative tests according to iris colour

\begin{tabular}{|c|c|c|c|}
\hline & \multicolumn{3}{|c|}{ IOP increase of $8 \mathrm{mmHg}$ or more } \\
\hline & \multicolumn{2}{|l|}{ Mydriasis test } & \multirow{2}{*}{$\begin{array}{l}\text { Dark-prone } \\
\text { test } \\
\text { e }\end{array}$} \\
\hline & Tropicamide & Homatropine & \\
\hline Heavily pigmented iris & 1 & $1^{*}$ & 5 \\
\hline Lightly pigmented iris & 4 & 0 & 2 \\
\hline Total & 5 & 1 & 7 \\
\hline
\end{tabular}

*This eye responded positively also to the dark-prone test (OD in patient no. 12).

Table 4 Results of tonography in one eye of patient no. 10

\begin{tabular}{lll}
\hline Specification & $C$ & Becker index \\
\hline Before laser iridectomy* & $0 \cdot 25$ & 100 \\
After laser iridectomy & $0 \cdot 07$ & 190 \\
\hline
\end{tabular}

${ }^{*}$ On pilocarpine treatment.

\section{Discussion}

The advantages of the argon laser over the surgical method in producing a patent coloboma are obvious and have been discussed. ${ }^{89}$ In all but one eye this treatment successfully controlled the IOP without the need for additional medication. The purpose of the various provocative tests is to assess the likelihood of the IOP's increasing in the future. We found a positive dark-prone test in $38 \%$ of the eyes compared with $22 \%$ in a surgical peripheral iridectomy study performed in our department (submitted for publication) and $60 \%$ reported. ${ }^{11}$

The mydriasis test after homatropine was positive in only one eye $(5.5 \%)$ as compared with $20 \%$ in our surgical iridectomy study. The mydriasis test after tropicamide was positive in $28 \%$ of the eyes. Yassur $e t$ $a l .{ }^{9}$ found a negative test in all but one eye of their series, yet they did not perform this test in their third group of eyes (chronic closed-angle glaucoma).

The difference between the occurrence of positive tests in the lightly and heavily pigmented irides is difficult to explain. It is known that mydriatics are less effective in dark eyes than in light ones ${ }^{12}$; thus the dilating effect of 2 drops of tropicamide on the individual pupil varied according to the iris colour.

The explanation for the higher percentage of positive dark-prone test results in eyes with heavily pigmented irides is speculative. The anterior displacement of the lens during the test is not influenced by the iris colour. Therefore the difference between the response of the eyes with heavily and lightly pigmented irides to the dark-prone test must lie in the pupil's diameter and/or the amount of pigment in the angle. The visual evaluation of the amount of dispersed pigment seen on gonioscopy is inaccurate. It is possible that pupils with heavily pigmented irides dilate to a less extent in darkness than pupils with lightly pigmented irides. Thus a pupillary block mechanism might more readily occur in the mid-dilated pupil.

The tonographic results seem to indicate the possibility of trabecular damage by the dispersed pigment following iridectomy. The normal tonographic results in the fellow eyes in cases with monocular laser iridectomy are not comparable, since all eyes were under treatment with pilocarpine, which influences the outflow facility. In our study group the majority of patients had chronic angle-closure glaucoma with trabecular damage, and therefore the discontinuation of pilocarpine treatment after iridectomy reduced the damage though the IOP was controlled. This explains also the change in the tonography results in patient no. 10 (Table 4.). Further studies are needed to compare tonographic results after laser iridectomy in patients with angleclosure glaucoma when the tonography before the procedure gives normal findings and the patient is kept on a regimen of pilocarpine after the procedure until the tonography is performed.

The possibility of retinal damage following laser iridectomy cannot be excluded. ${ }^{68}$ Fundus examination is not sufficient; static perimetry and fluorescein angiography are needed to evaluate this possibility, and our results are being prepared for publication.

\section{References}

1 Mayer-Schwickerath G. Erfahrungen mit der Lichtkoagulation der Netzhaut und der Iris. Doc Ophthalmol 1956; 10: 119-31.

2 Zweng HC, Flocks M, Kapany NS, Silbertrust BS, Peppers NA. Experimental laser photocoagulation. Am J Ophthalmol 1964; 58: 353-9.

3 Perkins ES, Brown NAP. Iridotomy with a ruby laser. $\mathrm{Br} J$ Ophthalmol 1973; 57: 487-98.

4 Khuri CH. Argon laser iridectomies. Am J Ophthalmol 1973; 76: 490-3.

5 Pollack IP, Patz A. Argon laser iridotomy: an experimental and clinical study. Ophthalmic Surg 1976; 7: 22-30.

6 Abraham RK. Procedure for outpatient argon laser iridectomies for angle-closure glaucoma. Int Ophthalmol Clin 1976; 16: 1-18.

7 Abraham RK, Miller GL. Outpatient argon laser iridectomy for angle-closure glaucoma: a two-year study. Trans Am Acad Ophthalmol Otolaryngol 1975; 79: OP 529-37.

8 Podos SM, Kels BD, Moss AP, Ritch R. Anders MD. Continuous wave argon laser iridectomy in angle-closure glaucoma. Am J Ophthalmol 1979; 88: 836-42.

9 Yassur Y, Melamed S, Cohen S, Ben-Sira I. Laser iridotomy in closed angle glaucoma. Arch Ophthalmol 1979; 97: 1920-1.

10 Schwartz LW. Spaeth GL. Argon laser iridotomy in primary angle-closure or pupillary block glaucoma. Trans Ophthalmol Soc UK 1980; 99: 257-63.

11 Hung PT, Chou LH. Provocation and mechanism of angle-closure glaucoma after iridectomy. Arch Ophthalmol 1979; 97: 1862-4.

12 Havener WH. Ocular Pharmacology. 3rd ed. Saint-Louis: Mosby, 1974: 221. 